\title{
AVALIAÇÃO DO USO DE ERVAS MEDICINAIS COMO SUPLEMENTO NUTRICIONAL DE FERRO, COBRE E ZINCO'
}

\author{
Édira Castello Branco de ANDRADE", Simone Pinheiro ALVES ${ }^{2}$, Iracema TAKASE
}

\section{RESUMO}

O cobre, ferro e zinco, considerados elementos essenciais ao corpo humano, apresentam biodisponibilidade variável em função da forma química que se encontram em um alimento. As ervas medicinais, amplamente utilizadas, podem apresentar novas indicacões quanto a suplementação destes metais. Este trabalho tem por objetivo avaliar os teores de cobre, ferro e zinco em ervas medicinais, pós e ervas secas, e promover a extração seqüencial visando a biodisponibilidade. Os teores de cobre, ferro e zinco foram determinados através da espectroscopia de absorção atômica. A extração seqüencial foi aplicada com os extratores cloreto de cálcio $1,0 \mathrm{M}$; ácido acético $0,1 \mathrm{M}$ com acetato de amônio $5 \%(\mathrm{pH}=5,0)$; ácido acético $0,5 \mathrm{M}$ e $\mathrm{HCl} 0,5 \mathrm{M}$. Os resultados apresentaram teores altos de cobre, ferro e zinco, quando comparados com outras fontes alimentícias destes metais, além de indicar que os mesmos se apresentam sob, no mínimo, 4 espécies químicas distintas nas ervas analisadas. O extrator I foi o de melhor eficiência para os três metais. Considerando que o consumo destas ervas é feito com visão farmacológica, acredita-se que uso das mesmas em preparos de alimentos pode favorecer a suplementação dos metais cobre, ferro e zinco.

Palavras-chave: ervas medicinais; cobre; ferro; zinco; biodisponibilidade; extração seqüencial.

\section{SUMMARY}

EVALUATION OF THE USE OF MEDICINAL GRASS AS NUTRITIONAL SUPPLEMENT OF IRON, COPPER AND ZINC. Copper, iron and zinc, considered essential elements in the human body, present changeable biodisponibility in chemical form more than if found in a food. Medicinal plants, widely used, can present new indications as to how much the suplementation of these metals, aiming at such an objective, can be shown to evaluate the amounts of copper, iron, and zinc in medicinal plants, powder and dry grass, and to promote the extraction sequencial aiming at the biodisponibility. The copper amount, iron and zinc had been determined through the spectroscopy of atomic absorption. The extraction sequencial was applied with the extractors calcium chloride $1,0 \mathrm{M}$; acetic acid $0,1 \mathrm{M}$ with ammonium acetate $5 \%(\mathrm{pH}=5,0)$; acetic acid $0,5 \mathrm{M}$ and $\mathrm{HCl} 0,5 \mathrm{M}$. The results had presented high copper amount, iron and zinc, when compared with other nourishing sources of these metals, besides indicating that the same ones if present under at the very least 4 distinct chemical species in the analyzed grass. The extracting (I) was of better efficiency for the three metals. Considering that the consumption of these grass is made with farmacological action, it is given credit that use of the same ones in foods can be used as fonts of these metals.

Keywords: medicinal plants; copper; iron; zinc; biodisponibility; sequencial extractios.

\section{1 - INTRODUÇÃO}

O cobre é um microelemento de número atômico 29 e peso atômico de 63,55, essencial para diversas funções como: mobilização do ferro para a síntese de hemoglobina, além de ser componente de várias enzimas (citocromo C-oxidase, superóxido desmutase, monoaminooxidase,etc.) $[12,16,27]$.

A absorção do cobre ocorre por transporte ativo e por difusão a nível duodenal. Em média, 40 a $50 \%$ do total ingerido são absorvidos. Uma vez absorvido é transportado para o figado ligado à albumina e transcupreina, incorporando-se então a ceruloplasmina e várias metaloenzimas, que permite o transporte do cobre pra os tecidos extra-hepáticos. A excreção é por via fecal e, em maior teor, pela bile, assim como a urina e suor. Sua deficiência pro-

\footnotetext{
Recebido para publicação em 12/04/2005. Aceito para publicação em 31/08/2005 (001509).

Departamento de Tecnologia de Alimentos, Escola de Nutrição, Universidade Federal do Estado do Rio de Janeiro. Endereço: Rua Xavier Sigaud, $n^{\circ}$ 290, Prédio II, 3o andar, Urca. CEP: 20211-040, Rio de Janeiro-RJ.E-mail: ediracba@unirio.com.br

Departamento de Química Analítica, Universidade Federal do Rio de Janeiro.

A quem a correspondência deve ser enviada.
}

voca anemia, leucopenia, neutropenia, hiperuricemia, retardo no crescimento; enquanto que sua toxicidade provoca diarréia, náusea, vômitos, cirrose, anemia e bronquite [12, 16, 27].

Sabe-se que o organismo humano adulto contém de 3 a $5 \mathrm{~g}$ de ferro, aproximadamente $2000 \mathrm{mg}$ como hemoglobina e $8 \mathrm{mg}$ como enzimas. Essas formas são muito importantes para a função ótima de um individuo. O ferro é bem conservado pelo organismo, onde $90 \%$ são recuperados e reutilizados intensivamente. A absorção desse mineral depende de vários fatores como dos estoques corporais, do conteúdo fornecido pela dieta e da fonte alimentar, além de receber influência dos outros alimentos ingeridos na mesma refeição $[8,10,19]$.

O ferro da dieta existe como ferro heme, encontrado na hemoglobina e na mioglobina e como ferro não heme. O ferro heme ( 5 a $10 \%$ do ferro da dieta) é absorvido nas células mucosas como um complexo de porfirina intacto. Contudo, sua absorção pode ser de até $25 \%$, comparada com $5 \%$, do ferro não heme [8].

O ferro não heme deve estar presente no duodeno e nojejuno superior sob forma solúvel para que seja absorvido. Com esse propósito, é ionizado pelo suco gástrico, reduzido ao estado ferroso e quelado com substâncias solubilizantes, tais como o ácido ascórbico. Conforme o quimo passa do estômago para o duodeno, a adição de secreções duodenais aumenta o $\mathrm{pH}$ para 7,0 , ponto no qual 
a maioria dos íons férricos está precipitada, a não ser que tenha sido quelado. $\mathrm{O}$ íon ferroso é significativamente mais solúvel em pH 7,0 e sendo assim, fica disponível para a absorção. Ressalta-se que a influência do ascorbarto é mais pronunciada em refeições inibitórias principalmente se estas contiverem altos teores de fitatos e polifenóis. Por outro lado, o efeito é menor em refeições que contêm alimentos fontes de ferro-heme (produtos cárneos) $[8,9,10,16]$.

O zinco é um microelemento de número atômico $30 \mathrm{e}$ peso atômico de 65,37 e possui funções semelhantes as do cobre como a constituição de enzimas, mas também apresenta outras específicas como a mobilização hepática da vitamina A e atuação no crescimento e maturação sexual, funções imunológicas, dentre outras $[12,16]$.

O processo de absorção do zinco é por difusão, no duodeno e jejuno. Em média 10 a $40 \%$ da ingestão oral é absorvido. Após liberar-se dos alimentos, o zinco forma complexo com ligante endógeno e exógeno, como a histidina, ácido cítrico e ácido picolínico. Esta absorção achase relacionada com a concentração proporcional inversa intralumial intestinal $[12,16,27]$.

O zinco passa para a corrente sangüínea por transporte ativo e combina-se com albumina e aminoácidos no teor de $55 \%$ e com macroglobulinas no teor de $40 \%$, não se destinando a uso metabólico [12, 16, 27].

O zinco é armazenado principalmente no figado e a excreção é feita via urinária. Sua deficiência provoca retardo no crescimento, falta de apetite, lesões cutâneas e alterações de comportamento, enquanto que sua toxicidade provoca náusea, vômitos, cefaléia e deficiência de cobre $[12,27]$.

O termo biodisponibilidade, proposto inicialmente para a área farmacológica, indica a proporção do nutriente que é absorvido e utilizado pelo organismo. Existem diversos fatores intrínsecos e extrinsecos que influenciam em um melhor ou pior aproveitamento dos nutrientes. Dentre os fatores intrínsecos podemos destacar: a espécie do nutriente, a matrix onde o nutriente está incorporado e a ligação molecular desse nutriente. Com relação aos fatores extrínsecos destacam-se: a quantidade desse nutriente na dieta associada às interações que ele pode sofrer, os atenuadores de bioconversão, o estado nutricional do individuo e os fatores genéticos e relacionados ao indivíduo. Sendo assim, a determinação do teor total do metal ingerido pelo organismo não possibilita traçar um perfil da eficiência de sua absorção $[9,20$, 23].

A técnica de especiação dos metais, que determina a concentração das formas físico-químicas individuais dos elementos que, em conjunto, constitui a concentração total do mesmo na amostra, possibilita a obtenção de novos dados para prever sua absorção [10 , 11, 12, 18, 24].

Para especiação em amostras sólidas, inicialmente deve ser aplicado um método de extração, que pode ser seletivo ou seqüencial. Um elemento pode estar presente em um sólido sob a forma de espécies adsorvidas na superficie, como precipitados, em sítios de troca iônica nas superfícies das partículas, co-precipitadas, ocluídos ou como compostos de coordenação. Quando a extração seqüencial é aplicada, baseia-se na progressão de extratores fracos, como a água, até um extrator forte, como um ácido concentrado [13, 14, 15, 21, 22, 25, 26].

A suplementação nutricional de minerais vem sedo cada vez mais utilizada. Formulações a base de sais de metais ou metais quelados são freqüentes na prescrição nutricional como suplemento. As ervas medicinais, usadas como chás ou como cápsulas, são comuns em nosso país, rico em medicamentos da flora. A indicação destas ervas, normalmente associada aos seus compostos orgânicos, é comum. O presente trabalho tem como objetivo avaliar o teor dos metais cobre, ferro e zinco em diferentes ervas medicinais e a biodisponibilidade dos mesmos através da extração seqüencial $[1,7]$.

\section{2 - MATERIAL E MÉTODOS}

\section{1 - Amostras}

Foram analisadas amostras de ervas medicinais consumidas na região sudeste, obtidas sob a forma de pós para preparo de medicamentos fitoterápicos $[\mathrm{F}]$ e forma de ervas secas utilizadas para preparo de chás [C]. As amostras analisadas foram boldo $(\mathrm{F})$, carqueja $(\mathrm{F})$, catuaba $(F, C)$, cavalinha $(F)$, erva de São João $(F, C)$, espinheira santa $(\mathrm{F}, \mathrm{C})$, guaraná $(\mathrm{F})$, jurubeba $(\mathrm{F}, \mathrm{C})$, pata de vaca $(F, C)$ e senne $(F, C)$. As amostras foram adquiridas em farmácia de manipulação da cidade do Rio de Janeiro.

\section{2 - Determinação do teor total de cobre, ferro e zinco}

Foi utilizado cerca de $1 \mathrm{~g}$ de amostra seca sendo calcinada em mufla a $550^{\circ} \mathrm{C}$ por um período minimo de 2 horas. O resíduo obtido foi dissolvido em $\mathrm{HCl} 2 \mathrm{~mol} / \mathrm{L}$ e avolumado a $25 \mathrm{~mL}$. O teor total nas amostras foi determinado através da espectrometria de absorção atômica em chama. A determinação dos teores de cobre, ferro e zinco foi feita em triplicata.

\section{3 - Extração seqüencial}

Foram utilizados cerca de $2 \mathrm{~g}$ de amostra dos pós e $1 \mathrm{~g}$ de amostra das ervas secas e cada amostra passou por processo de extração seqüencial. Os extratores utilizados foram: solução de cloreto de cálcio 1,0M; solução de ácido acético $0,1 \mathrm{M}$ com acetato de amônio $5 \%[\mathrm{pH}=5,0]$; solução de ácido acético $0,5 \mathrm{M}$ e solução de $\mathrm{HCl} 0,5 \mathrm{M}$. Cada extrator esteve em contato com a amostra durante 1 hora, sendo depois filtrado, e este utilizado para determinação do teor total de cobre, ferro e zinco. O processo de extração foi feito em triplicata

\section{4 - Tratamento estatístico} [16].

Os teste de Dixon e T de Student foram aplicados 


\section{5 - Garantia da qualidade}

Na análise dos metais cobre, ferro e zinco por espectroscopia de absorção atômica, o aparelho foi sempre previamente calibrado com solução analítica do respectivo metal.

\section{3 - RESULTADOS E DISCUSSÃO}

As Tabelas 1 e 2 apresentam o teor total de cobre, ferro e zinco em ervas em pó e secas, respectivamente.

TABELA 1 - Teor total de cobre, ferro e zinco em mg\% em ervas medicinais (pós)

\begin{tabular}{lccc}
\hline \multicolumn{1}{c}{ Amostras } & $\begin{array}{c}\text { Cobre mg/100g } \\
\text { amostra }\end{array}$ & $\begin{array}{c}\text { Ferro mg/100g } \\
\text { amostra }\end{array}$ & $\begin{array}{c}\text { Zinco mg/100g } \\
\text { amostra }\end{array}$ \\
\hline Boldo & $0,73 \pm 0,03$ & $2,59 \pm 0,33$ & $1,68 \pm 0,12$ \\
Carqueja & $1,27 \pm 0,04$ & $2,70 \pm 0,02$ & $5,56 \pm 0,04$ \\
Catuaba & $0,67 \pm 0,06$ & $3,10 \pm 0,55$ & $2,40 \pm 0,10$ \\
Cavalinha & $0,44 \pm 0,02$ & $3,39 \pm 0,25$ & $3,98 \pm 0,13$ \\
Erva São João & $1,33 \pm 0,08$ & $2,75 \pm 0,06$ & $3,34 \pm 0,12$ \\
Espinheira Santa & $0,61 \pm 0,07$ & $2,25 \pm 0,45$ & $2,08 \pm 0,24$ \\
Guaraná & $1,93 \pm 0,04$ & $2,66 \pm 0,29$ & $2,07 \pm 0,09$ \\
Jurubeba & $1,44 \pm 0,03$ & $5,70 \pm 0,59$ & $2,68 \pm 0,20$ \\
Pata de Vaca & $0,91 \pm 0,14$ & $3,44 \pm 0,94$ & $2,96 \pm 0,09$ \\
Senne & $1,16 \pm 0,20$ & $2,25 \pm 0,02$ & $3,32 \pm 0,01$ \\
\hline
\end{tabular}

TABELA 2 - Teor total de cobre, ferro e zinco em mg\% em ervas medicinais (secas)

\begin{tabular}{lccc}
\hline \multicolumn{1}{c}{ Amostras } & $\begin{array}{c}\text { Cobre mg/100g } \\
\text { amostra }\end{array}$ & $\begin{array}{c}\text { Ferro mg/100g } \\
\text { amostra }\end{array}$ & $\begin{array}{c}\text { Zinco mg/100g } \\
\text { amostra }\end{array}$ \\
\hline Catuaba & $1,37 \pm 0,03$ & $4,55 \pm 0,37$ & $2,18 \pm 0,24$ \\
Erva São João & $1,82 \pm 0,06$ & $5,44 \pm 0,29$ & $4,72 \pm 0,28$ \\
Espinheira Santa & $1,22 \pm 0,10$ & $4,00 \pm 0,33$ & $2,72 \pm 0,08$ \\
Jurubeba & $2,67 \pm 0,06$ & $4,17 \pm 0,13$ & $2,88 \pm 0,30$ \\
Pata de Vaca & $1,23 \pm 0,13$ & $5,03 \pm 0,50$ & $2,77 \pm 0,19$ \\
Senne & $0,78 \pm 0,05$ & $5,31 \pm 0,60$ & $3,66 \pm 0,30$ \\
\hline
\end{tabular}

É possivel observar que as ervas apresentam uma diferença significativa entre os teores dos metais nas duas formas de apresentação, pó e erva seca. Na maioria das amostras os teores de cobre, ferro e zinco são superiores na forma de erva seca em comparação às formas de pós.

Em média, as ervas medicinais em pó apresentaram $1,05 \mathrm{mg} \%$ de cobre e as ervas secas $1,52 \mathrm{mg} \%$. ANDRADE et al. [2, 3, 4, 5, 6] analisando esse metal em frutas [2]; hortaliças do tipo C [3]; cereais [4]; hortaliças tipos A e B [5]; e em leguminosas [6], encontraram teores médios de cobre de $0,13 \mathrm{mg} \%, 0,21 \mathrm{mg} \%, 0,09 \mathrm{mg} \%, \quad 0,08 \mathrm{mg} \%$, $0,24 \mathrm{mg} \%$ e $0,89 \mathrm{mg} \%$, respectivamente.

Os teores médios de ferro encontrados nas amostras de ervas medicinais em pó e secas foram, respectivamente, $3,19 \mathrm{mg} \%$ e 4,75mg\%. Segundo MARTÍNEZ et al. [19], a quantidade de ferro em leguminosas é de 5,3-8,5 mg\%. Em outros alimentos como, agrião, alface, chicória, couve e nozes, também considerados como boas fontes de ferro, este mineral se encontra nos respectivos teores médios de 2,60mg\%, 1,10 mg\%, 1,50 mg\%, 2,20 mg\% e 2,10 $\mathrm{mg} \%$. [12,19].

Em relação ao zinco, as ervas medicinais em pó apresentaram teor médio de $2,93 \mathrm{mg} \%$ e as ervas secas de $3,16 \mathrm{mg} \%$. Em cereais [4], frutas [2], hortaliças do tipo C [3] e leguminosas [6], este mineral se encontra em média, respectivamente, $\quad 1,55 \mathrm{mg} \%, \quad 0,18 \mathrm{mg} \%, \quad 0,33 \mathrm{mg} \% \quad$ e $3,16 \mathrm{mg} \%$.

Apesar da maioria das ervas apresentarem um teor alto dos metais cobre, ferro e zinco, o consumo medicamentoso destas ervas sob a forma de pós é normalmente de $1 \mathrm{~g}$ ao dia, o que caracteriza um baixo teor dos metais. Mas, estas ervas podem ser utilizadas como matériaprima na fabricação de produtos alimentícios, obviamente considerando sua toxicidade, ai sim podendo ser consideradas boas fontes destes metais.

A Tabela 3 e a Figura 1 apresentam os teores de cobre extraídos pelo processo de extração seqüencial. É possível observar que todas as amostras apresentam o cobre em no mínimo 4 espécies químicas distintas. Verifica-se que os extratores I e IV foram os que apresentaram melhor eficiência, isto caracteriza a presença de compostos facilmente solúveis, como sais (ação extrator I) e complexos deste metal (ação extrator IV). Comparando os resultados com os obtidos por ANDRADE, TEODORO \& TAKASE [5] em hortaliças dos tipos A e B, verifica-se que para aquelas amostras também o cobre se encontrava em no mínimo 4 espécies químicas distintas, o extrator I sendo considerado o de maior eficiência, mas o perfil de extração não se assemelha aos das ervas ora estudadas. Interessante observar, que com exceção do Senne, as demais ervas que se apresentam tanto sob a forma de pós como de erva seca, tiveram o perfil de extração semelhante $[14,15,17]$.

TABELA 3 - Extração seqüencial de cobre em mg\% de ervas medicinais pós (1) erva seca (2)

\begin{tabular}{lcccc}
\hline \multicolumn{1}{c}{ Amostras } & I & II & III & IV \\
\hline Boldo (1) & $0,30 \pm 0,04$ & $0,12 \pm 0,02$ & $0,09 \pm 0,01$ & $0,13 \pm 0,01$ \\
Carqueja (1) & $0,29 \pm 0,01$ & $0,17 \pm 0,01$ & $0,12 \pm 0,01$ & $0,28 \pm 0,03$ \\
Catuaba (1) & $0,26 \pm 0,00$ & $0,10 \pm 0,01$ & $0,10 \pm 0,00$ & $0,24 \pm 0,03$ \\
Cavalinha (1) & $0,13 \pm 0,01$ & $0,12 \pm 0,01$ & $0,08 \pm 0,00$ & $0,12 \pm 0,00$ \\
Erva São João (1) & $0,28 \pm 0,01$ & $0,23 \pm 0,01$ & $0,14 \pm 0,01$ & $0,17 \pm 0,01$ \\
Espinheira Santa (1) & $0,34 \pm 0,01$ & $0,12 \pm 0,01$ & $0,09 \pm 0,00$ & $0,11 \pm 0,00$ \\
Guaraná (1) & $0,44 \pm 0,04$ & $0,17 \pm 0,03$ & $0,11 \pm 0,01$ & $0,53 \pm 0,05$ \\
Jurubeba (1) & $0,30 \pm 0,04$ & $0,20 \pm 0,01$ & $0,16 \pm 0,01$ & $0,26 \pm 0,04$ \\
Pata de Vaca (1) & $0,16 \pm 0,02$ & $0,13 \pm 0,01$ & $0,11 \pm 0,01$ & $0,18 \pm 0,01$ \\
Senne (1) & $0,25 \pm 0,02$ & $0,18 \pm 0,02$ & $0,13 \pm 0,01$ & $0,19 \pm 0,05$ \\
Catuaba (2) & $0,35 \pm 0,00$ & $0,14 \pm 0,01$ & $0,18 \pm 0,02$ & $0,29 \pm 0,01$ \\
Erva São João (2) & $0,69 \pm 0,04$ & $0,38 \pm 0,01$ & $0,25 \pm 0,01$ & $0,57 \pm 0,00$ \\
Espinheira Santa (2) & $0,51 \pm 0,04$ & $0,16 \pm 0,01$ & $0,09 \pm 0,02$ & $0,25 \pm 0,04$ \\
Jurubeba (2) & $0,72 \pm 0,01$ & $0,33 \pm 0,02$ & $0,24 \pm 0,01$ & $0,68 \pm 0,10$ \\
Pata de Vaca (2) & $0,40 \pm 0,02$ & $0,31 \pm 0,02$ & $0,19 \pm 0,01$ & $0,35 \pm 0,05$ \\
Senne (2) & $0,49 \pm 0,05$ & $0,08 \pm 0,01$ & $0,04 \pm 0,01$ & $0,22 \pm 0,05$ \\
LEGENDA - I - Solução de cloreto de cálcio - 1M pH 7; II - Soluçăo ácido acético- \\
0,1M com Acetato de amônio - 5\% pH 5,0; III - Solução de ácido acético - 0,5M; \\
IV - Soluçáo de ácido clorídrico - 0,5M.
\end{tabular}

A Tabela 4 e Figura 2 apresentam os resultados obtidos da extração seqüencial do ferro.

É possivel verificar que a maioria das amostras apresenta o ferro sob no mínimo 4 espécies químicas diferentes. Os extratores I e IV foram os de maior eficiência, como no caso do cobre, mas o perfil de extração é diferente. Interessante observar, que as ervas espinheira santa e senne, apesar de apresentarem em cerca de $50 \%$ a mais do teor do metal quando sob a forma de erva seca, em relação a forma de pó, o perfil de extração é semelhante, o que não ocorre com as outras ervas. 


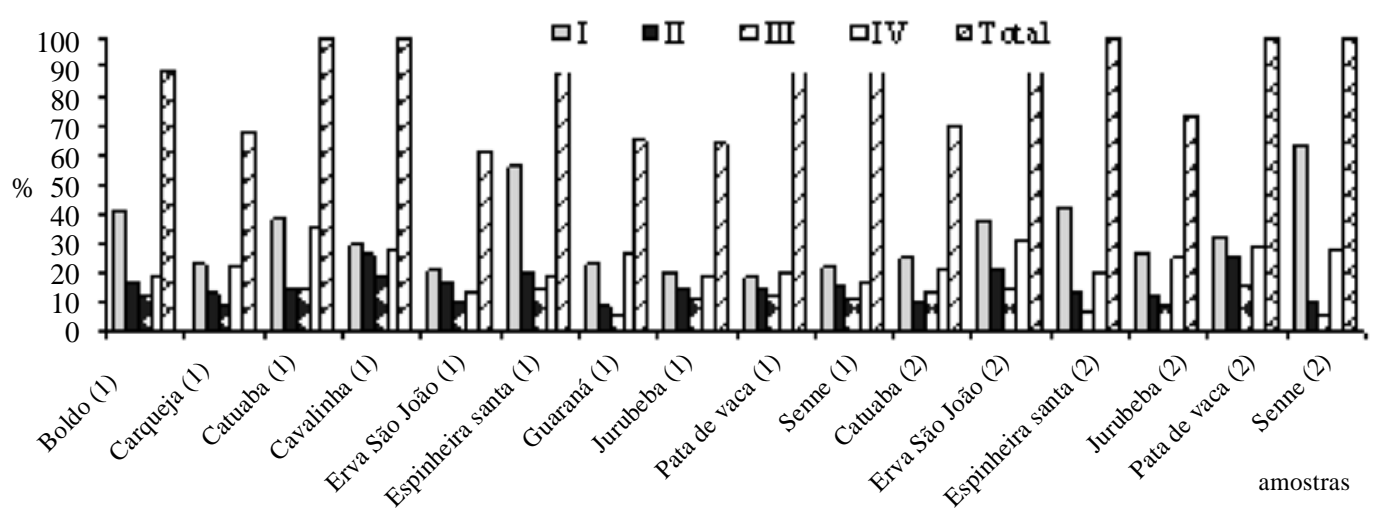

FIGURA 1 - Teor \% de cobre em extratos de ervas medicinais em pó (1) e ervas secas (2) N = 3

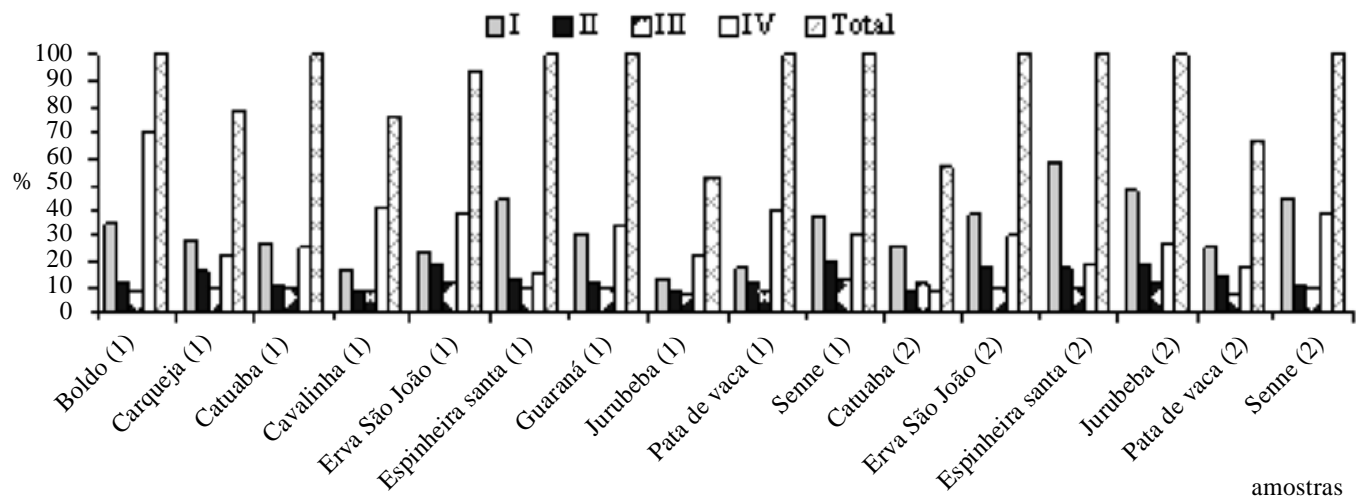

FIGURA 2 - Teor \% de ferro em extratos de ervas medicinais em pó (1) e ervas secas (2) $\mathrm{N}=3$

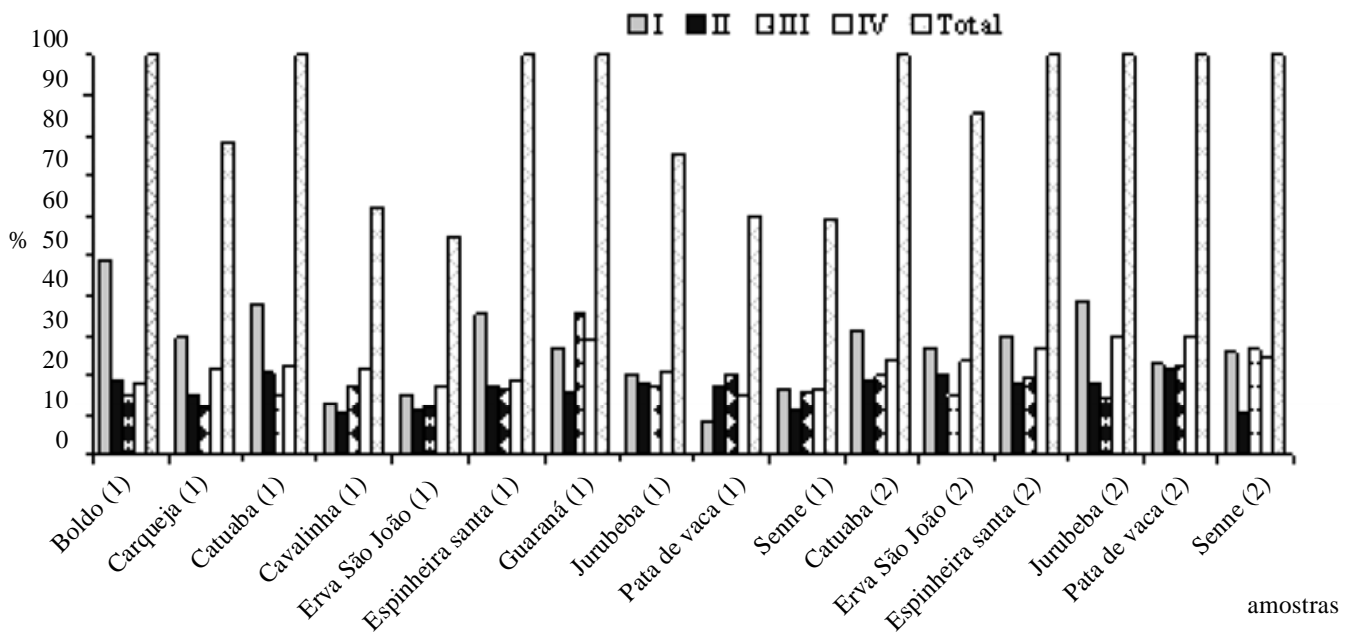

FIGURA 3 - Teor \% de zinco em extratos de ervas medicinais em pó (1) e ervas secas (2) $\mathrm{N}=3$ 
TABELA 4 - Extração seqüencial de ferro em mg\% de ervas medicinais pós (1) erva seca (2)

\begin{tabular}{lcccc}
\hline \multicolumn{1}{c}{ Amostras } & I & II & III & IV \\
\hline Boldo (1) & $0,89 \pm 0,12$ & $0,31 \pm 0,01$ & $0,23 \pm 0,01$ & $1,79 \pm 0,12$ \\
Carqueja (1) & $0,78 \pm 0,04$ & $0,44 \pm 0,01$ & $0,27 \pm 0,02$ & $0,61 \pm 0,04$ \\
Catuaba (1) & $0,86 \pm 0,05$ & $0,35 \pm 0,01$ & $0,32 \pm 0,08$ & $0,80 \pm 0,14$ \\
Cavalinha (1) & $0,57 \pm 0,03$ & $0,32 \pm 0,02$ & $0,30 \pm 0,01$ & $1,40 \pm 0,06$ \\
Erva São João (1) & $0,66 \pm 0,03$ & $0,52 \pm 0,08$ & $0,32 \pm 0,01$ & $1,07 \pm 0,25$ \\
Espinheira Santa (1) & $0,99 \pm 0,03$ & $0,32 \pm 0,02$ & $0,22 \pm 0,02$ & $0,34 \pm 0,02$ \\
Guaraná (1) & $0,81 \pm 0,10$ & $0,32 \pm 0,01$ & $0,26 \pm 0,02$ & $0,91 \pm 0,01$ \\
Jurubbeba (1) & $0,79 \pm 0,06$ & $0,51 \pm 0,05$ & $0,41 \pm 0,01$ & $1,31 \pm 0,42$ \\
Pata de Vaca (1) & $0,61 \pm 0,04$ & $0,42 \pm 0,03$ & $0,28 \pm 0,05$ & $1,39 \pm 0,11$ \\
Senne (1) & $0,85 \pm 0,04$ & $0,45 \pm 0,11$ & $0,30 \pm 0,02$ & $0,68 \pm 0,11$ \\
Catuaba (2) & $1,22 \pm 0,03$ & $0,43 \pm 0,04$ & $0,56 \pm 0,02$ & $0,38 \pm 0,04$ \\
Erva São João (2) & $2,11 \pm 0,10$ & $0,93 \pm 0,06$ & $0,57 \pm 0,04$ & $1,65 \pm 0,10$ \\
Espinheira Santa (2) & $2,35 \pm 0,20$ & $0,68 \pm 0,02$ & $0,42 \pm 0,07$ & $0,77 \pm 0,17$ \\
Jurubeba (2) & $2,01 \pm 0,01$ & $0,79 \pm 0,07$ & $0,51 \pm 0,00$ & $1,13 \pm 0,26$ \\
Pata de Vaca (2) & $1,28 \pm 0,13$ & $0,76 \pm 0,01$ & $0,37 \pm 0,03$ & $0,94 \pm 0,06$ \\
Senne (2) & $2,37 \pm 0,21$ & $0,57 \pm 0,05$ & $0,52 \pm 0,02$ & $2,05 \pm 0,14$ \\
\hline LEGENDA - I - Solução de cloreto de cálcio - 1M pH 7; II - Soluçăo ácido acético- \\
0,1M com Acetato de amônio - 5\% pH 5,0; III - Soluçăo de ácido acético - 0,5M; \\
IV - Solução de ácido cloridrico - 0,5M.
\end{tabular}

TABELA 5 - Extração seqüencial de zinco em mg\% de ervas medicinais pós (1) erva seca (2)

\begin{tabular}{|c|c|c|c|c|}
\hline \multirow[t]{2}{*}{ Amostras } & \multicolumn{4}{|c|}{ Extratores } \\
\hline & I & II & III & IV \\
\hline Boldo (1) & $0,81 \pm 0,06$ & $0,32 \pm 0,07$ & $0,25 \pm 0,02$ & $0,30 \pm 0,01$ \\
\hline Carqueja (1) & $1,63 \pm 0,06$ & $0,84 \pm 0,05$ & $0,69 \pm 0,09$ & $1,21 \pm 0,22$ \\
\hline Catuaba (1) & $90 \pm 0,03$ & $0,49 \pm 0,02$ & $0,36 \pm 0,01$ & $0,53 \pm 0,08$ \\
\hline Cavalinha (1) & $, 52 \pm 0,01$ & $0,41 \pm 0,02$ & $0,68 \pm 0,02$ & $0,87 \pm 0,05$ \\
\hline Erva São Joắo (1) & $, 52 \pm 0,02$ & $0,37 \pm 0,00$ & $0,39 \pm 0,02$ & $0,56 \pm 0,05$ \\
\hline Espinheira Santa (1) & $0,74 \pm 0,04$ & $0,35 \pm 0,02$ & $0,34 \pm 0,01$ & $0,39 \pm 0,03$ \\
\hline Guar & $0,56 \pm 0,09$ & $0,33 \pm 0,03$ & $0,74 \pm 0,10$ & $0,60 \pm 0,04$ \\
\hline Juru & $0,54 \pm 0,02$ & $0,47 \pm 0,07$ & $0,45 \pm 0,04$ & $0,57 \pm 0,06$ \\
\hline Pata de Vac & $0,25 \pm 0,04$ & $0,51 \pm 0,03$ & $0,60 \pm 0,06$ & $0,43 \pm 0,05$ \\
\hline Senne (1) & $0,55 \pm 0,02$ & $0,36 \pm 0,07$ & $0,52 \pm 0,10$ & $0,54 \pm 0,11$ \\
\hline Catu & $68 \pm 0,03$ & $0,41 \pm 0,05$ & $0,44 \pm 0,04$ & $0,52 \pm 0,10$ \\
\hline o João & $1,29 \pm 0,06$ & $0,95 \pm 0,22$ & $0,68 \pm 0,00$ & $1,10 \pm 0,07$ \\
\hline eira Santa (2) & $0,82 \pm 0,09$ & $0,49 \pm 0,05$ & $0,53 \pm 0,05$ & $0,73 \pm 0,06$ \\
\hline & $1,12 \pm 0,01$ & $0,53 \pm 0,05$ & $0,41 \pm 0,02$ & $0,86 \pm 0,03$ \\
\hline Pata de Vaca (2) & $0,63 \pm 0,06$ & $0,60 \pm 0,10$ & $0,61 \pm 0,06$ & $0,82 \pm 0,06$ \\
\hline Senne (2) & $0,95 \pm 0,05$ & $0,39 \pm 0,05$ & $0,97 \pm 0,06$ & $0,91 \pm 0,19$ \\
\hline
\end{tabular}

A Tabela 5 e a Figura 3 apresentam os teores extraídos de zinco das ervas medicinais estudadas.

O zinco, também se apresenta para a maioria das ervas analisadas sob a forma de no mínimo 4 espécies químicas distintas. Para a maioria das amostras, os extratores II, III e IV apresentaram eficiência de extração similar. O de melhor eficiência para a maioria das amostras é o extrator I. As ervas, erva de São João e senne apresentam perfil de extração similar nas formas de pó e ervas secas.

Considerando que o extrator I age sob formas iônicas, que apresentam biodisponibilidade desfavorecida pelos processos de absorção destes metais, e que o extrator IV, que age sob compostos orgânico, complexos sugerindo uma melhor biodisponibilidade através dos mecanismos de absorção ativa, acredita-se que o ferro se torna mais biodisponivel seguido do zinco e cobre nas ervas analisadas. Técnicas de identificação destes metais nos extratos obtidos podem favorecer na elucidação da biodisponibilidade dos metais analisados $[14,15,17]$

\section{4 - CONCLUSÕES}

As ervas medicinais apresentam um teor percentual alto de cobre, ferro e zinco quando comparados às fontes vegetais destes metais. No processo de extração seqüencial verifica-se que estes metais se encontram sob no mínimo 4 espécies químicas distintas nas amostras analisadas, sendo o extrator I o de melhor eficiência para os três metais. Considerando que o consumo destas ervas é feito com visão farmacológica, acredita-se que uso de ervas em preparos de alimentos pode favorecer a suplementação dos metais cobre, ferro e zinco.

\section{5 - REFERÊNCIAS BIBLIOGRÁFICAS}

[1] ALVES, T.M. Biological screening of Brazilian medicinal plants, Mem. Inst. Oswaldo Cruz, v. 95, n. 3, p 367-73, 2000.

[2] ANDRADE, E.C.B.; ASSIS, A.S.; FERREIRA, F.N.; MELLO, V.S.; TAKASE, I. Determinação dos teores de cobre e zinco em frutas, ANAIS, XVIII CBCTA, ISBN 8589123-1-4, 2002.

[3] ANDRADE, E.C.B.; BARROS, A.M.; ASSIS, A.S.; FERREIRA, F.N.; MELLO, V.S.; TAKASE, I. Avaliação dos teores de cobre e zinco em hortaliças C cruas e após processamento térmico em meio salino e aquoso, ANAIS, XVIII CBCTA, ISBN 85-89123-01-4, 2002.

[4] ANDRADE, E.C.B.; BARROS, A.M.; MAGALHÃES, A.C.P.; CASTRO, L.L.S.; TAKASE, I. Avaliação da biodisponibilidade de cobre e zinco em cereais crus e processados termicamente em meio aquoso e salino. Revista Brasileira de Nutrição Clínica, v. 17, n. 3, p. 79-82, 2002.

[5] ANDRADE, E.C.B.; TEODORO, A . J.; TAKASE, I. Determinação dos teores de cobre em diferentes extratos de hortaliças do tipo A e B. Ciênc. Tecnol. Aliment., v. 24, n. 2, p. 159-310, abr-jun. 2004.

[6] ANDRADE, E.C.B.; BARROS, A.M.; MAGALHÃES, A.C.P.; CASTRO, L.L.S.; TAKASE, I. Avaliação dos teores de cobre e zinco em leguminosas cruas e após processamento térmico em meio salino e aquoso, ANAIS, XVIII CBCTA, ISBN 85-89123-01-4, 2002.

[7] CORREA, M.P, Dicionário das Plantas Uteis do Brasil e das Exóticas Cultivadas, Instituto Brasileiro de Desenvolvimento Florestal, 1984.

[8] COUTINHO,R.; Noções de Fisiologia da Nutrição, 2 ed; Rio de Janeiro: Cultura Médica, 1981.

[9] COZZOlino, SilviA M. F. Biodisponibilidade de Minerais. Revista Nutrição, Campinas, p. 87-98, jul-dez 1997.

[10] DUTRA DE OLIVEIRA, J.F.; MARCHINI, J.S. Ciências nutricionais, São Paulo: Sarvier, 1998.

[11] FAIRWEATHER-TAIT,S.J., Bioavaibility of dietary minerals. Biochemical Transactions Colchester, v. 24 , n. 3, p 775-780, 1996.

[12] FRANCO, G.. Tabela de Composição de Alimentos. 9 ed. São Paulo: Editora Atheneu, p 239-241, 268-269, 1999.

[13] GALLARDO-LARA, F.; AZCON, M.; QUESADA, J.L.; POLO, A. Phytoavaibility and Extractability of Copper and Zinc in Calcareous Soil Amended with Composted Urban Wastes. Journal of Environmental Science and Health, B, v. 34, p 1049-1064, 1999. 
[14] GLEYZES, C.; TELLIER, S.; ASTRUC, M. Fractionation studies of trace elements in contaminated Soils and sediments: a review of sequential extraction procedures Trends in Analytical Chemistry, v. 21, p. 6-7, 2002.

[15] IPOLY, J.; BRUNORI, C.; CREMISINI, C.; FODOR, P.; MACALUSO, L.; MORABITO, R. Evaluation of performance of time saving extraction devices in the BCR-three-step sequential extraction procedure. Journal Environmtal Monitoring, aug, v. 4, 4, p 541-8, 2002.

[16] LEHNINGER, A.L., NELSON, D.L.; COX, M.M. Principios de Bioquímica, 2 ed., São Paulo: Sarvier, 1998.

[17] LOON, J.C.V \& BAREFOOT, R.R. Overwiew of analytical methods for elemental speciation- speciation in environmental and biological sciences, 15-22, 1991.

[18] MAHAN L.K.; ESCOTT-STUMP, S. Krause: Alimentos, Nutrição \& Dietoterapia. São Paulo: Editora Roca; 1998.

[19] MARTINEZ C, ROS G;. PERIAGO M, LÓPEZ G;. Biodisponibilidad del Hierro de los Alimentos. Archivos Latino-Americanos de Nutrição, v. 49, n.2, p.106-113, 1999.

[20] MILLER, J.; MILLER, J. Statistics and chemometrics for analytical chemistry, 4 ed., Inglaterra, Prentice Hall, 2001.

[21] QIAN, J.; WANG, Z.; SHAN, X.; TU, Q.; WEN, B.; CHEN, B. Evaluation of plant availability of soil trace metals by chemical Fractionation d multiple regression analysis, Environmental Pollution, v. 91, n. 3, p 309-315, 1996.

[22] RAMOS, L.; Gonzales, M.T.; HERnANDEZ, L.M.; Sequential Extraction of Copper, Lead, Cadmium, and Zinc in Sediments from Ebro River [Spain]: Relationship with Levels Detected in Earthworms. Bulletin of Environmental Contamination and Toxicology, v. 62, n. 3, p 301-308, 1999.

[23] SANDSTORM, B. Micronutrientes interactions:effects on absorption and bioavaibility. The British Journal of Nutrition, may, 85 Suppl 2:S181-5, 2001

[24] SANZ-MEDEL, A. Trace element analytical speciation in biological systems: importance, challenges and trens. Spectrochimica Acta Part B, n 53, p197-2 11, 1998.

[25] SCHEINOST, A.C.; KRETZSCHMAE, R.; PFISTER, S.; ROBERTS, D.R. Combine selective sequential extraction, $\mathrm{X}$-ray absorption spectroscopy, and principal components analysis in soil. Environmental Science \& Techonology, dec, v. 1, p. 36, 2002.

[26] SHIOWATANA, J.; TANTIDANAI, N.; NOOKABKAEW, S.; NACAPRICHA, D. A novel continuous flow sequential extraction procedure for metal speciation in solids. Journal of Environmtal Quality, jul-aug, n. 30; 2001.

[27] WAITZBERG, D. L. Nutrição Oral, Enteral e Parenteral na Prática Clínica. 3ed São Paulo: Editora Atheneu, p.131-134, 2002. 